\title{
Evaluating lane-by-lane gap-out based signal control for isolated intersection under stop-line, single and multiple advance detection systems
}

\author{
Chandan Kancharla1 ${ }^{1}$ Alvaro M. Seco ${ }^{2}$ e Ana Bastos Silva ${ }^{3}$
}

\begin{abstract}
In isolated intersection's actuated signal control, inductive loop detector layout plays a crucial role in providing the vehicle information to the signal controller. Based on vehicle actuations at the detector, the green time is extended till a pre-defined threshold gap-out occurs. The Federal Highway Administration (FHWA) proposed various guidelines for detector layouts on low-speed and high-speed approaches. This paper proposes single and multiple advance detection schemes for low-speed traffic movements, that utilizes vehicle actuations from advance detectors located upstream of the stop-line, which are able to detect spill-back queues. The proposed detection schemes operate with actuated signal control based on lane-bylane gap-out criteria. The performance of the proposed schemes is compared with FHWA's stop-line and single advance detection schemes in the VISSIM simulation tool. Results have shown that the proposed single advance detection schemes showed improved performance in reducing travel time delay and average number of stops per vehicle under low volumes while the multiple advance detection scheme performed well under high volumes.
\end{abstract}

Keywords: Actuated signal control, advance detectors, gap-out, lane-by-lane detection, FHWA, VISSIM.

Resumo: Nos sistemas semaforizados atuados os detetores por indução constituem a forma mais comum para recolha de informação de tráfego. Com base nessa informação o tempo de verde é incrementado sucessivamente até atingir um valor máximo, sendo o processo interrompido quando o intervalo de atuações ultrapassar um valor pré-estabelecido. A Federal Highway Administration (FHWA) propõe vários esquemas para localização dos detetores adaptados a diferentes ambientes rodoviários. Este artigo apresenta propostas de localização de detetores baseados na aplicação de um ou de múltiplos detetores, a montante da entrada. Os esquemas propostos são baseados num sistema de sinais luminosos com funcionamento atuado, onde os incrementos dos tempos de verde são avaliados usando, de forma separada por via de entrada, um intervalo crítico entre veículos sucessivos como critério de referência. O nível de desempenho do sistema foi comparado com o resultante dos esquemas de referência do FHWA baseados em detetor único, num caso colocado junto à linha de stop, no outro com localização avançada, recorrendo à plataforma de microssimulação VISSIM. Os resultados comprovam que, face a níveis de procura de tráfego baixos, a utilização de um detetor isolado permite atingir melhor desempenho, traduzido na redução das demoras e do número de paragens por veículo, enquanto para elevados níveis de procura a adoção de múltiplos detetores tende a resultar em melhores resultados.

Palavras-chave: Sinais semaforizados atuados, detetores de avanço, intervalo crítico de extensão, deteção individualizada por via, FHWA, VISSIM.

\section{INTRODUCTION}

Signalized intersections are an important part of the road transportation system that regulates the traffic flow in urban areas. Correct installation of traffic signals along with proper signal control strategy will minimize delays, stops and fuel consumption for all road users. Traffic signals usually operate in either fixed time or actuated mode or combination of both. The fixed time signal consists of a series of cycle lengths that are fixed in duration. On the other hand, actuated control consists of varied cycle lengths whose intervals are called and extended in response to vehicle detectors. Detection is used to provide real-time information about traffic demand to the controller. The green time of each phase is determined by detector input and corresponding signal control parameters (Koonce, 2008).

\footnotetext{
${ }^{1}$ Chandan Kancharla, Department of Civil Engineering, UC.

(chandan@uc.pt)

2 Alvaro M. Seco, Department of Civil Engineering, UC. (aseco@dec.uc.pt)

${ }^{3}$ Ana Bastos Silva, Department of Civil Engineering, UC

(abastos@dec.uc.pt)
}

Manuscrito recebido em 21/04/2016 e aprovado para publicação em 28/06/2016

Este artigo é parte de TRANSPORTES v. 24, n. 3, 2016. ISSN: 2237-1346 (online). DOI:10.4237/transportes.v24i3.1142
In actuated control, minimum green time is provided to every phase to serve the queued-up vehicles from the red part of the cycle, and the green time is either continued until no vehicles are detected over a short gap-out time (or extension time) or extended until the maximum green is reached if the vehicles continue to arrive within the gap-out time. Thus the amount of green times in an actuated control can be flexible between the minimum and maximum green times. Detector layout (i.e., location and size) plays a very important role in passing the vehicle actuation information to the signal controller. The performance of the intersection operation mainly depends on the relationship between the detection layout and the signal controller settings. For optimum performance, the detector layout and signal settings should be balanced to the geometry of the intersection, its traffic volume, and the approach speed. The balancing process consists of adjusting the detector location (with respect to the stop-line), detector length, passage time, and minimum green time for the prevailing conditions (Koonce, 2008).

Many adaptive traffic control systems worldwide use different detection layouts to estimate the state of traffic. SCATS, which is a two-level hierarchical system developed in Australia (Sims and Dobinson, 1980) uses information from vehicle detectors, located in each lane immediately in advance of the stop-line. SCOOT, which is a dynamic, online, real-time method of signal control developed in 
U.K. (Hunt et al., 1982) uses upstream detection to collect its traffic information. SCOOT's upstream detectors are usually installed in the vicinity of the previous upstream intersection to reduce communication costs. MOVA, which is a vehicle actuated signal control system developed by Transport Research Laboratory (TRL), U.K. (DfT, 1997) uses an advance detector layout to provide traffic data to the control logic. Each lane in MOVA system consists of one vehicle detector about $100 \mathrm{~m}$ before the stop-line, and a second one at approximately $40 \mathrm{~m}$. Adaptive Control Software Lite (ACS Lite), which is developed by FHWA in USA uses stop-line detectors (sized from 4 to $70 \mathrm{ft}$ or 1.22 to $21 \mathrm{~m}$ long) to monitor the volume and occupancy on green. On arterial approaches where progression is required, ACS Lite uses advance detectors $(6 \mathrm{ft} \times 6 \mathrm{ft}$ or $1.83 \mathrm{~m} \times 1.83 \mathrm{~m}$ size $)$ to monitor cyclic flow profile, to identify platoon arrivals, and use this information for adjustment of offsets to improve progression (Stevanovic, 2010).

The Federal Highways Administration (FHWA), which is a body of expertise in road transportation of the United States Department of Transportation (USDoT), has given guidelines for various detector layouts to be used for a fully actuated signal control for an isolated intersection. The objective of this paper is to analyze various detection layouts and evaluate their performance when applied to an isolated intersection through simulation.

\section{BACKGROUND}

\subsection{Detector layouts}

The objective of the detection process is to detect the vehicle's presence and identify gaps in traffic, which, depending on their duration, will lead to the phase being ended or the green being extended. Many authors in the past have proposed detector layout criteria for actuated traffic signal control (Bonneson et al., 1994; Lin, 1985; Hulscher, 1976; Kay et al., 1975).

Bonneson et al (2009) states that stop-line detection is a very effective means of ensuring that a waiting queue is given the time it needs to clear the intersection. This type of detection allows the controller to be responsive to the presence of waiting vehicles and to minimize the percentage of cycles that end unnecessarily before the queue has been cleared. However, the major limitation of using only stopline detection is the gap-out time will be known only maximum allowable headway (MAH) seconds after the vehicle crosses the stop line, causing unnecessary extension of green at the end of each phase.

Koonce (2008) and Bonneson et al (2009) have suggested guidelines for the detection design of low-speed traffic movements (speeds less than or equal to $56 \mathrm{kmph}$ ). The main objective of the detection of low-speed traffic movements is "to call a phase and serve the queue while minimizing the delays" (Koonce, 2008). Stop-line detection is used on low-speed approaches because there is less emphasis on protection from the dilemma zone on the approach. According to Lin (1985), the ideal length of the stop-line detection zone is about $24 \mathrm{~m}$. This length is very efficient in detecting the end of queue while minimizing the chance of a premature gap-out (which occurs when the unit extension time is too short and the green ends before serving the queue adequately). However, the installation and maintenance of such a long detector are often cost prohibitive. Hence FHWA has suggested that, the appropriate length of the stop-line detection zone should not be smaller than $6 \mathrm{~m}$ and the detector should be operated in presence mode (see Figure 1). In a presence mode detection, the actuation starts when the vehicle arrives to the detection zone and ends only after the vehicle leaves the detection zone (Bonneson et al., 2009).

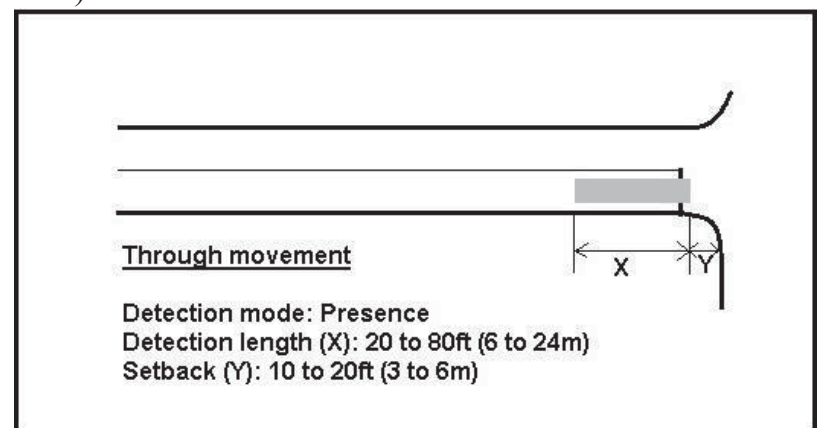

Figura 1. Stop-line detection design for low-speed through movement (Bonneson et al., 2009)

Tabela 1. Recommended distance ( $\mathrm{Z}$ ) between stop-line and detector (Koonce, 2008)

\begin{tabular}{cc}
\hline $\begin{array}{c}\text { 85th Percentile Approach } \\
\text { Speed, } \mathbf{k m p h}\end{array}$ & $\begin{array}{c}\text { Distance, } \mathbf{Z} \text { (m) for MAH } \\
\text { 3.0seconds }\end{array}$ \\
\hline 32 & 27 \\
40 & 33 \\
48 & 40 \\
56 & 47 \\
\hline
\end{tabular}

If advance detection is used for low-speed traffic movements, according to FHWA's guidelines, one $1.83 \mathrm{~m}$ detector should be located upstream of the stop-line which operates in pulse mode. In pulse mode, the actuation starts and ends with the arrival of the vehicle to the detector (typical pulse actuation is about 0.10 to $0.15 \mathrm{~s}$ ) (Bonneson et al., 2009). "The location of the advance detector should be such that the travel time from the detector to the stop-line for a vehicle traveling at the 85 th percentile speed is equal to the maximum allowable headway (MAH)"(Koonce, 2008). The advantage of such advance detection over stop-line detection is, the unnecessary extension of green time is prevented by a vehicle that has crossed the stop-line. Based on this principle, the recommended location for the detector for different approach speeds is listed in Table 1.

For high-speed approaches (speeds greater than $56 \mathrm{kmph}$ ), the objective of the detection design is to be able to serve the queue at the beginning of green and also to safely terminate the phase during a conflicting call. According to FHWA's guidelines, stop-line detection should be used to clear the queues and multiple upstream detectors should be used to safely terminate the phase (Koonce, 2008; Zimmerman and Bonneson, 2006).

The objective of the work presented here is to test the actuated signal control for an isolated intersection, using the vehicle actuations from stop-line, single and multiple advance detectors. Since FHWA has recommended to use multiple upstream detectors for high-speed approaches, this paper focusses only on low-speed approaches where no recommendations are made by FHWA to use multiple advance detectors, which it was considered to be a potentially competitive alternative worth being tested. 


\subsection{Gap-out based signal control}

For vehicle detection associated with multiple detectors, two types of traffic detection schemes were seen as current research practice: single-channel detection and lane-by-lane detection (Smaglik et al., 2005; Tian and Urbanik, 2006). A single-channel detection method connects all detectors in all lanes on an approach into a single detection unit and provides a single input to the signal phase. Therefore, when any detector on the approach detects a vehicle, the controller resets the gap-out timer for that phase and the green phase extends. The phase terminates only when the entire approach gaps out. Such a detection scheme may cause unnecessary green extensions based on the desired headway, particularly for the approaches that have more than one lane. In a lane-by-lane detection scheme, each lane is monitored with a separate detector and gap-out timer. Under this method, the green phase terminates only when all the lanes on an approach have individually reached the desired gap-out condition (Wang Xuan, 2008).

Tian and Urbanik (2006) presented an example to understand the difference between the single-lane and laneby-lane gap-out detection schemes. The same kind of example, with different numbers is presented in this paper. Table 2 shows a sample of vehicle detection times and their associated headway gaps on a two-lane approach. Assuming a 3.0s of MAH, when a headway gap is greater than $3.0 \mathrm{~s}$, a gap-out condition occurs and the phase terminates.

In case of single-channel detection, to determine when the gap-out condition occurs and the resulting green extension time, the vehicle detection times in both lanes are combined and sorted in sequence, and the headway gaps are calculated (see Table 3). The numbers in bold represent the vehicles in Lane 2. For the data shown in Table 3, a gap-out condition would occur in 17.2s when the following headway is $3.5 \mathrm{~s}(>3.0 \mathrm{~s})$. So the phase would terminate at $17.2 \mathrm{~s}$ $(14.2+3.0)$.

Tabela 2. Vehicle detection times and headway gaps on a two-lane approach

\begin{tabular}{cccc}
\multicolumn{4}{c}{ Lwo-lane approach } \\
\hline $\begin{array}{c}\text { Lane-1 } \\
\begin{array}{c}\text { Dehicle } \\
\text { time (s) }\end{array}\end{array}$ & $\begin{array}{c}\text { Lane-2 } \\
\text { Headway (s) }\end{array}$ & $\begin{array}{c}\text { Vehicle } \\
\text { Detection } \\
\text { time (s) }\end{array}$ & $\begin{array}{c}\text { Headway } \\
\text { gap (s) }\end{array}$ \\
\hline 1.6 & & 1.9 & \\
3.2 & 1.6 & 3.8 & 1.9 \\
5.2 & 2.0 & 5.3 & 1.5 \\
6.8 & 1.6 & 7.3 & 2.0 \\
10.0 & $3.2)>3.0)$ & 8.9 & 1.6 \\
11.8 & 1.8 & 12.7 & $3.8(>3.0)$ \\
17.7 & 5.9 & 14.2 & 1.5 \\
\hline
\end{tabular}

Tabela 3. Combined vehicle detection times and headway gaps on a two-lane approach

\begin{tabular}{cccc}
\hline Combined & \multicolumn{3}{c}{ Combined } \\
\hline $\begin{array}{c}\text { Vehicle } \\
\text { detection }\end{array}$ & Headway & $\begin{array}{c}\text { Vehicle } \\
\text { detection }\end{array}$ & Headway \\
\hline Time (s) & Gap (s) & Time (s) & Gap (s) \\
\hline 1.6 & & $\mathbf{7 . 3}$ & 0.5 \\
$\mathbf{1 . 9}$ & 0.3 & $\mathbf{8 . 9}$ & 1.6 \\
3.2 & 1.3 & 10.0 & 1.1 \\
$\mathbf{3 . 8}$ & 0.6 & 11.8 & 1.8 \\
5.2 & 1.4 & $\mathbf{1 2 . 7}$ & 0.9 \\
$\mathbf{5 . 3}$ & 0.1 & $\mathbf{1 4 . 2}$ & 1.5 \\
6.8 & 1.5 & 17.7 & $3.5(>3.0)$ \\
\hline
\end{tabular}

In case of lane-by-lane detection, the headways in each lane are monitored separately by the detectors, and the phase would gap-out when both lanes individually reach the gap-out condition. As shown in Table 2, Lane-1 first reaches gap-out after the vehicle detection at $6.8 \mathrm{~s}$ when the following headway gap is $3.2 \mathrm{~s}(>3.0 \mathrm{~s})$, and Lane-2 reaches gap-out after the vehicle detection at $8.9 \mathrm{~s}$ when the following headway gap is $3.8 \mathrm{~s}(>3.0 \mathrm{~s})$. Therefore, a gap-out condition would occur at $8.9 \mathrm{~s}$, and the phase would terminate at $11.9 \mathrm{~s}(8.9+3.0)$. In this particular example, the lane-bylane detection results in $5.3 \mathrm{~s}$ less green extension than the single-channel detection. This could decrease the overall delay of the intersection.

Wang Xuan (2008) analyzed the gap-out logic with single-channel and lane-by-lane detection schemes. Laneby-lane detection was observed to more easily reach the gap-out condition and provided efficient signal timing solutions. Two scenarios related to the MAH of 2.5 seconds and 3.0 seconds were analyzed. It was found that a 2.5 -second $\mathrm{MAH}$ was able to produce better intersection performance compared to a 3.0-second MAH under the same vehicle detection scheme.

Smaglik et al (2005) also compared the traditional vehicle detection, in which all lanes on an approach are connected to an actuated controller through one amplifier card and input, and lane-by-lane detection, in which each lane is interfaced with the controller through separate amplifier cards and inputs. Various MAH (2.0, 2.5, 3.0, 3.5, and 4.0 seconds) scenarios were tested and concluded that implementation of lane-by-lane detection with 3.0s MAH showed 3 to $5 \%$ benefits.

No research has been found in literature investigating the performance of the different detection schemes, using lane-by-lane gap-out signal control criteria. This paper attempts to evaluate two kinds of FHWA's detection schemes: stop-line detection, one advance detector upstream of the stop-line. To achieve better performance compared to those layouts, an alternative multiple advance detection scheme is proposed which consists of two advance detectors upstream of the stop-line.

\section{EVALUATION OF VARIOUS DETECTION SCHEMES}

This section presents various detection schemes that are used for evaluation through simulation. Note that all the detection schemes that are presented below will be analyzed under the same platform of fully-actuated lane-by-lane gapout signal timing criteria, assuming MAH of 3.0 seconds.

\subsection{FHWA's Stop-line detection scheme}

According to Koonce (2008) guidelines, for lowspeed approaches, the stop-line detection zone length should not be smaller than $6 \mathrm{~m}$ (see Figure $2 \mathrm{a}$ ) and the detector should be operating in presence mode. When laneby-lane detection with gap-out criteria is applied, the green phase for the approach terminates when all lanes have individually reached the desired gap-out (3.0 seconds) condition. The main limitation in this scheme is, the gap-out time will be known, only MAH seconds after the vehicle crosses the stop-line, thereby causing a delay of 3.0 seconds per lane per phase. 


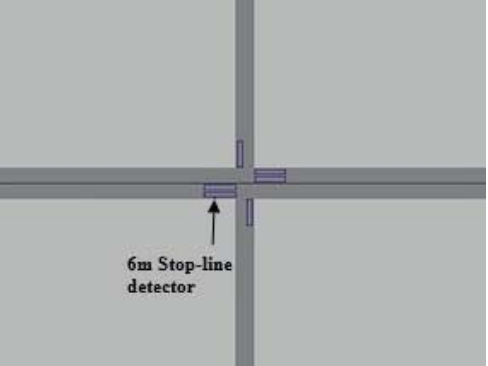

(a) Stop-line detection

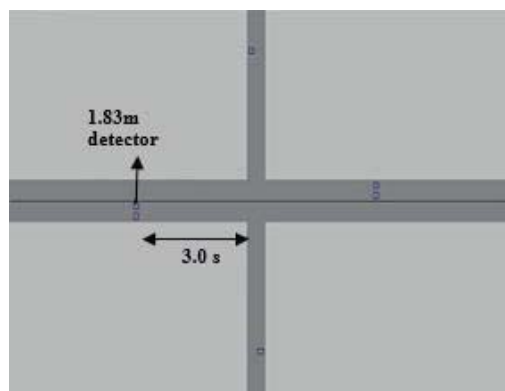

(b) Single advance detection

Figura 2. FHWA's Detection schemes

\subsection{FHWA's $1.83 \mathrm{~m}$ single advance detection scheme}

According to Koonce (2008) guidelines, for lowspeed approaches, if an advance detector is used, one $1.83 \mathrm{~m}$ detector is located upstream of the stop-line. The advance detector should be located such that the travel time from the detector to the stop-line for a vehicle traveling at the $85^{\text {th }}$ percentile speed is equal to the maximum allowable headway ( 3.0 seconds). In Figure $2 b$, a $1.83 \mathrm{~m}$ detector is located at a distance of $40 \mathrm{~m}$ before the stop-line, assuming the $85^{\text {th }}$ percentile approach speed is $48 \mathrm{kmph}$. Similarly, the location of the advance detector varies for different approach speeds (see Table 1).

In this scheme, minimum green is provided to serve the queued-up vehicles between stop-line and the upstream detector and the green phase is continued till gap-out condition occurs with MAH of 3.0 seconds in individual lanes or maximum green is reached. The advantage of this scheme over stop-line detection scheme is, the gap-out time will be known in advance at the upstream detector and the last vehicle will be able to cross the stop-line when the gapout period is reached and the phase terminates immediately. The main limitation of this detection layout is, during highvolume and congested situations the queues could extend beyond the advance detector, causing a premature gap-out that will leave a portion of the stopped queue unserved and, thereby, leading to increased delays and possible queue spillback.

\subsection{Proposed $6 \mathrm{~m}$ single advance detection scheme}

Similar to the FHWA's single advance detection scheme as in section 3.1, an alternative layout is proposed in this section, using a $6 \mathrm{~m}$ presence mode detector placed at $40 \mathrm{~m}$ before the stop-line (see Figure 3a). In this scheme, minimum green is also provided to serve the queued-up vehicles between stop-line and the upstream detector and the green phase is continued till gap-out (MAH 3.0 seconds) condition occurs in individual lanes or maximum green is reached. The advantage of this scheme over the FHWA's $1.83 \mathrm{~m}$ advance detection scheme is, due to its long detection zone and presence mode operation, the $6 \mathrm{~m}$ detector could be able to detect more vehicles and calls for green extension and thereby reducing the occurrences of premature gap-out situation.

\subsection{Proposed multiple advance detection scheme}

To acquire and utilize more vehicle information, an alternative layout is proposed where one $6 \mathrm{~m}$ presence mode detector and one $1.83 \mathrm{~m}$ pulse mode detector are used in each lane upstream of the stop-line (see Figure $3 b$ ).

- Detector-1 $(6 \mathrm{~m})$ is located (based on the average approach speeds) such that, a vehicle after crossing Detector-1 will take at least 3 seconds to cross the Detector-2.

- Detector-2 $(1.83 \mathrm{~m})$ is located (based on the average ap-proach speeds) such that, a vehicle after crossing Detector-2 will take at least 3 seconds to cross stopline.

The main advantage of this detection layout is the fact that the $6 \mathrm{~m}$ detector (due to its presence mode) is long enough to detect the stopped or slow moving queue which is spilled back the $1.83 \mathrm{~m}$ detector, thereby extends the green interval without causing premature gap-out situation. Once the minimum green period is expired, the $6 \mathrm{~m}$ detector calls for a green extension until the gap-out condition occurs with MAH of 3.0 seconds on each lane individually. Once gapout occurs at $6 \mathrm{~m}$ detectors, the $1.83 \mathrm{~m}$ detectors are activated and the green time is extended until the gap-out condition occurs with MAH of 3.0 seconds on each lane individually. The lane-by-lane gap-out logic for multiple detection scheme is presented in Figure 4. Since multiple advance detectors are used, more vehicle information is used by the signal controller and hence, it was believed, that this strategy could perform better than both the FHWA's stop-line and single advance detector strategies.

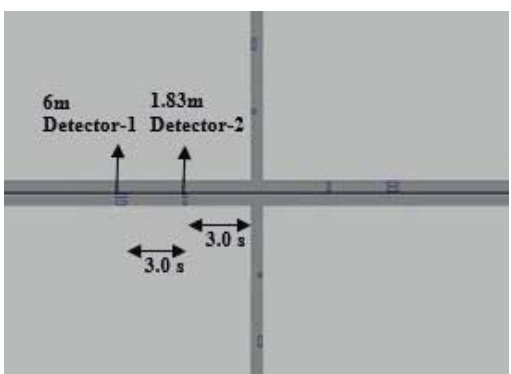

(b) Proposed multiple advance detection

(a) Proposed single advance detection

Figura 3. Proposed detection schemes. 


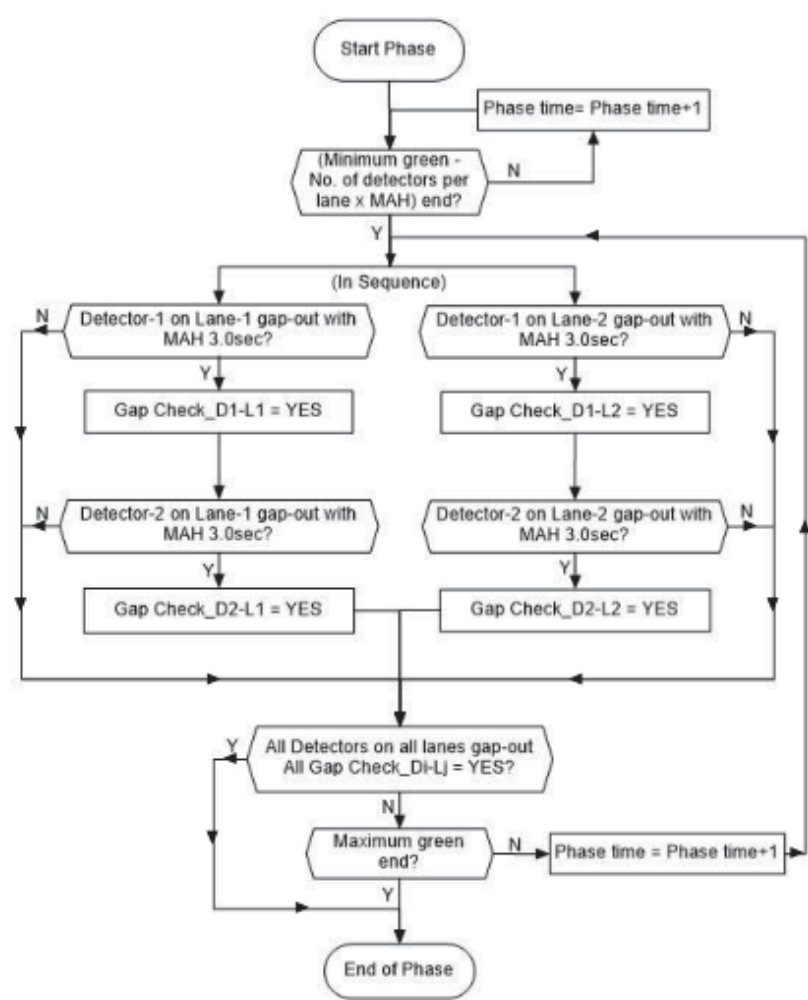

Figura 4. Lane-by-lane gap-out logic for multiple advance detection scheme

A major concern to most agencies installing traffic signals is the increased capital costs associated with any new equipment. According to the costs database of Intelligent transportation system office of USDoT, a $1.83 \mathrm{~m} \mathrm{x}$ $1.83 \mathrm{~m}$ loop detector costs $\$ 1,100$ (ITSJPO, 2014). This is minor in comparison to a cost of $\$ 47,300.00$ for a vehicle detection station with 2 lanes in each direction which includes 2 loops per lane (ITSJPO, 2014). All that is required is to customize the loop size according to the proposed layout.

\section{SIMULATION TESTS}

\subsection{Simulation framework}

The testing and evaluation of all the detection layouts as mentioned in section 3 is performed on a simple hypothetical four-legged isolated intersection as shown in Figure 5 .

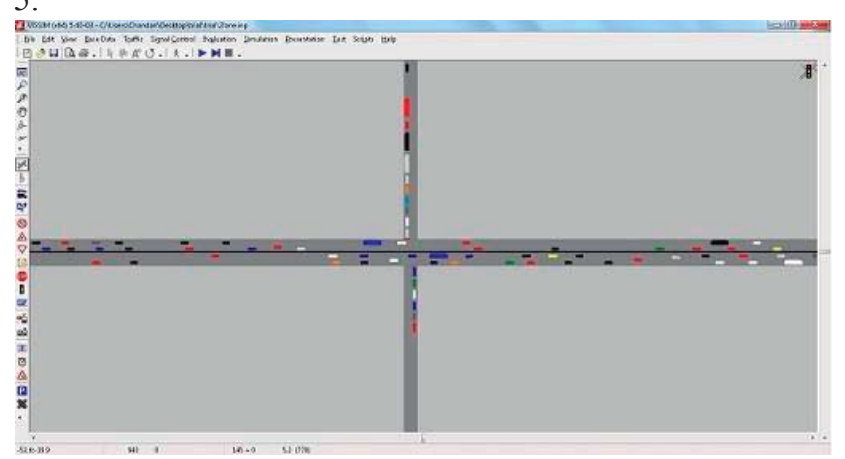

Figura 5. Snapshot of test intersection in VISSIM.

Each approach on the major road has two lanes (1 km long) with one-way through movement only. Each approach on the minor road has one lane (1 km long) with oneway through movement only. The approach width is taken as $3.5 \mathrm{~m}$ per lane. Simulation tests were carried in VISSIM 5.40 microscopic simulation software (PTV, 2012). VISSIM allows the users to access the vehicle information from the detectors and manipulate the traffic signal timings via a COM Application Programming Interface (API). The signal timing algorithms with lane-by-lane gap-out criteria for all the four detection layouts were coded in $\mathrm{C}++$ language and were integrated with VISSIM's COM interface. A simple two-phased timing plan is applied to allow only through movements during the simulation.

Simulation is run for 3900 seconds in which the first 300 seconds is used as warm-up time. The results of various scenarios are based on the average of 10 random seeds. Cars and Heavy vehicles (HV) are used in the simulation. During VISSIM trial simulation runs, using the default calibration parameters values defined in VISSIM, the saturation flow rate for the simulated intersection was found to be 2030 $\mathrm{pcu} / \mathrm{hr} / \mathrm{lane}$, which was then used to identify the input flows corresponding to the different $\mathrm{V} / \mathrm{C}$ traffic scenarios. The $\mathrm{ab}-$ solute maximum cycle length was taken as $120 \mathrm{sec}$. Amber time and all-red time was taken as 3 and 2 seconds per phase, respectively. The minimum green for major roads (EB and $\mathrm{WB}$ ) and minor roads (NB and $\mathrm{SB}$ ) was taken as 15 and 10 seconds respectively as per the guidelines in Koonce (2008). The maximum green for major and minor roads was taken as the proportion of major and minor road flow, multiplied by the maximum cycle length, after deducing the amber time and all red time. To compare the evaluation results of different detector layouts, travel time delay and average number of stops per vehicle were used as measures of effectiveness. Table 4 presents different sets of input flows for different volume to capacity ratios, which were used in the different analysis scenarios.

Tabela 4. Input flows for different $\mathrm{V} / \mathrm{C}$ ratios

\begin{tabular}{ccccc}
\hline & \multicolumn{2}{c}{$\begin{array}{c}\text { Major road } \\
\mathbf{( 7 0 \%} \text { flow) }\end{array}$} & \multicolumn{2}{c}{$\begin{array}{c}\text { Minor road } \\
(\mathbf{3 0 \%} \text { flow) }\end{array}$} \\
\cline { 2 - 5 } V/C & $\begin{array}{c}\text { East } \\
\text { bound }\end{array}$ & $\begin{array}{c}\text { West } \\
\text { bound }\end{array}$ & $\begin{array}{c}\text { North } \\
\text { bound }\end{array}$ & $\begin{array}{c}\text { South } \\
\text { bound }\end{array}$ \\
\cline { 2 - 5 } (veh/h) & (veh/h) & (veh/h) & (veh/h) \\
\hline 0.4 & 1040 & 520 & 223 & 112 \\
0.5 & 1300 & 650 & 279 & 140 \\
0.6 & 1560 & 780 & 335 & 167 \\
0.7 & 1820 & 910 & 391 & 195 \\
0.8 & 2080 & 1040 & 446 & 223 \\
0.9 & 2340 & 1170 & 502 & 251 \\
1.0 & 2600 & 1300 & 558 & 279 \\
\hline
\end{tabular}

1. East and West bound approaches has two lanes each. North and South bound approaches has one lane each

\subsection{Simulation scenarios and results}

Three sets of scenarios were evaluated in which traffic conditions were varied by varying v/c ratio, varying the proportions of Cars and HV's in total flow, varying the proportion of traffic flow on major and minor streets, in order to understand whether the relative performance of different detection schemes depends on the network congestion levels.

\subsubsection{Variation of volume to capacity ratio}

In this scenario, input flow from Table 4 is assigned according to different $\mathrm{v} / \mathrm{c}$ ratios. The proportion of cars and $\mathrm{HV}$ in total flow are kept constant as shown in Table 5. The simulation results of this scenario are shown in Figure 6. 
CHANDAN, K.; SECO, M.A.; SILVA, B.A.

Tabela 5. Variation in volume to capacity ratio for different traffic composition

\begin{tabular}{ccccc}
\hline V/C & $\begin{array}{c}\text { Percent } \\
\text { Cars in total flow }\end{array}$ & $\begin{array}{c}\text { Car Desired speed (kmph) } \\
\text { (Min-Max) }\end{array}$ & $\begin{array}{c}\text { Percent } \\
\text { HV's in total flow }\end{array}$ & $\begin{array}{c}\text { HV Desired seepd (kmph) } \\
\text { (Min-Max) }\end{array}$ \\
\hline 0.40 & 90 & $45-58$ & 10 & $40-45$ \\
0.50 & 90 & $45-58$ & 10 & $40-45$ \\
0.60 & 90 & $45-58$ & 10 & $40-45$ \\
0.70 & 90 & $45-58$ & 10 & $40-45$ \\
0.80 & 90 & $45-58$ & 10 & $40-45$ \\
0.90 & 90 & $45-58$ & 10 & $40-45$ \\
1.00 & 90 & $45-58$ & 10 & $40-45$ \\
\hline
\end{tabular}

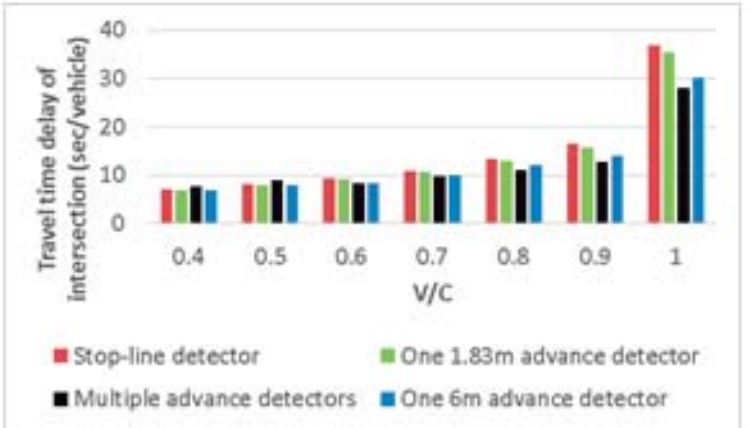

(a) Travel time delay vs V/C

Figura 6. Variation of $\mathrm{V} / \mathrm{C}$ ratio.

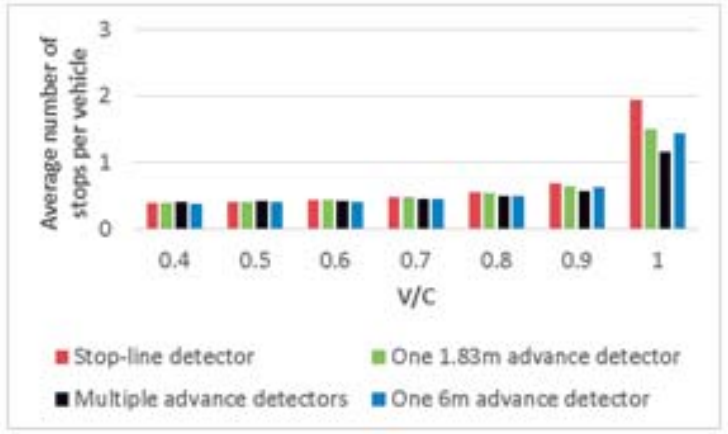

(b) Average number of stops per vehicle vs $\mathrm{V} / \mathrm{C}$
From the results in Figures 6 it can be observed that, for $\mathrm{v} / \mathrm{c}$ ratios from 0.60 to 1.0 , the multiple advance detection scheme showed reductions in delays, ranging from $9.1 \%$ to $20.5 \%$, and reductions in average number of stops per vehicle, ranging from $3.5 \%$ to $22.1 \%$, when compared to the $1.83 \mathrm{~m}$ single advance detection scheme results. When compared to the proposed $6 \mathrm{~m}$ single advance detection scheme, the multiple advance detection scheme showed reductions in delays between $3 \%$ to $6.5 \%$ of for $\mathrm{v} / \mathrm{c}$ ratios from 0.7 to 1.0 .

Due to the prese $1.83 \mathrm{~m}$ detectors, the multiple detection scheme clearly took advantage of detecting queued vehicles during high $\mathrm{v} / \mathrm{c}$ ratios and congestion situations, thus placing more calls for green extension. However, for lower v/c ratios ( 0.4 and 0.5$)$, the performance of the multiple advance detection scheme was worse when compared to all other detection schemes. At lower v/c ratios, because of low traffic volume and due to the MAH gap-out conditions of both $6 \mathrm{~m}$ and $1.83 \mathrm{~m}$ detectors on individual lanes, the travel time delay for the multiple advance detection scheme was higher when compared to all other detection schemes. Further, during low v/c ratios the proposed $6 \mathrm{~m}$ advance detection scheme has shown better performance over all other schemes.

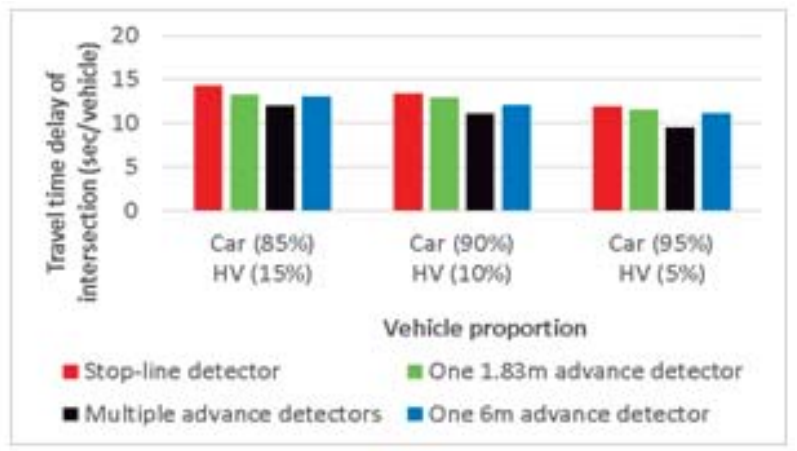

(a) Travel time delay vs Vehicle proportion

\subsubsection{Variation in proportion of type of vehicles in total flow}

In this scenario, v/c ratio is kept constant as 0.8 and the proportion of Cars and HV's are varied in the total input flow as shown in Table 6.

\begin{tabular}{ccccc}
\multicolumn{5}{c}{ Tabela 6. Variation in vehicle type proportion } \\
\hline V/C & $\begin{array}{c}\text { Percent } \\
\text { Cars in } \\
\text { total } \\
\text { flow }\end{array}$ & $\begin{array}{c}\text { Car desired } \\
\text { speed } \\
\text { (kmph) } \\
\text { (Min-Max) }\end{array}$ & $\begin{array}{c}\text { Percent } \\
\text { HV's in } \\
\text { total } \\
\text { flow }\end{array}$ & $\begin{array}{c}\text { HV desired } \\
\text { speed } \\
\text { (kmph) } \\
\text { (Min-Max) }\end{array}$ \\
\hline 0.80 & 85 & $48-58$ & 15 & $40-45$ \\
0.80 & 90 & $48-58$ & 10 & $40-45$ \\
0.80 & 95 & $48-58$ & 5 & $40-45$ \\
\hline
\end{tabular}

The results show that the higher the proportion of HV's, the higher is the travel time delay and average number of stops per vehicle (see Figure 7). This is because, due to the lower speeds HV's in total flow causes the Cars that are travelling behind them, to reduce their speeds. In this scenario, the multiple advance detection scheme has shown better performance compared to FHWA's stop-line detection, $1.83 \mathrm{~m}$ single advance detection scheme and the proposed $6 \mathrm{~m}$ advance detection scheme, with the benefits being higher when the proportion of HV's were low in the total flow. When the HV's proportion was $5 \%$ in total flow,

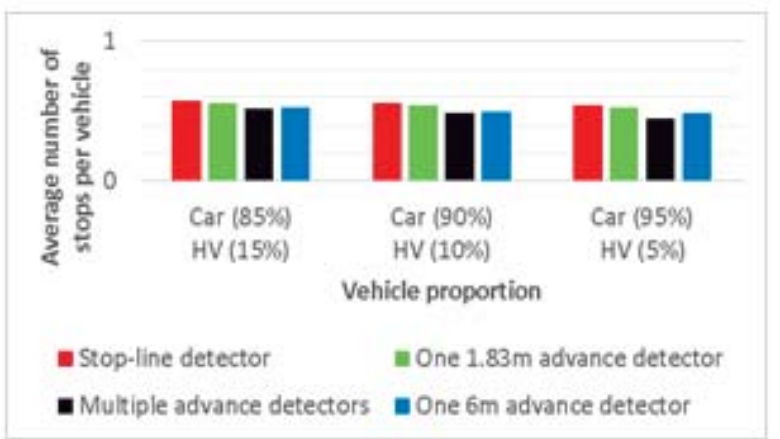

(b) Average number of stops per vehicle vs Vehicle proportion vehicle proportion 
Tabela 7. Variation in major road-minor road flow proportion

\begin{tabular}{cccccc}
\hline $\begin{array}{c}\text { Major road } \\
\text { flow proportion }\end{array}$ & $\begin{array}{c}\text { Minor road } \\
\text { flow proportion }\end{array}$ & $\begin{array}{c}\text { East } \\
\text { bound } \\
\text { (veh/h) }\end{array}$ & $\begin{array}{c}\text { West } \\
\text { bound } \\
\text { (veh/h) }\end{array}$ & $\begin{array}{c}\text { North } \\
\text { bound } \\
\text { (veh/h) }\end{array}$ & $\begin{array}{c}\text { South } \\
\text { bound } \\
\text { (veh/h) }\end{array}$ \\
\hline $60 \%$ & $40 \%$ & 1787 & 894 & 596 & 298 \\
$70 \%$ & $30 \%$ & 2080 & 1040 & 446 & 223 \\
$80 \%$ & $20 \%$ & 2383 & 1192 & 298 & 149 \\
$90 \%$ & $10 \%$ & 2681 & 1341 & 149 & 75 \\
\hline
\end{tabular}

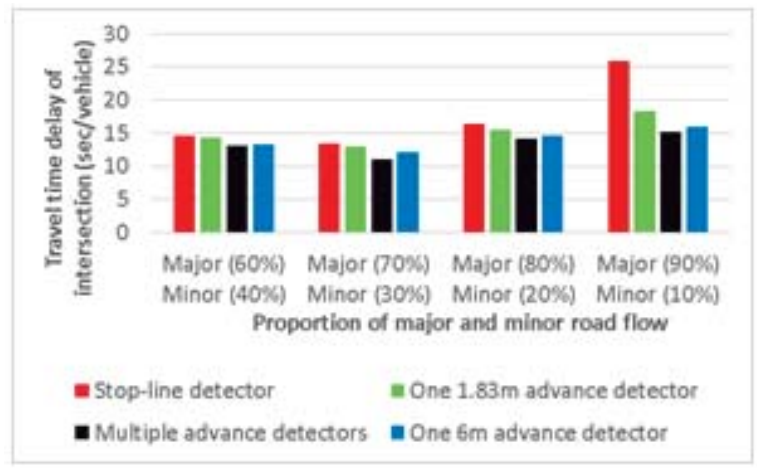

(a) Travel time delay vs Major and minor road flow proportion

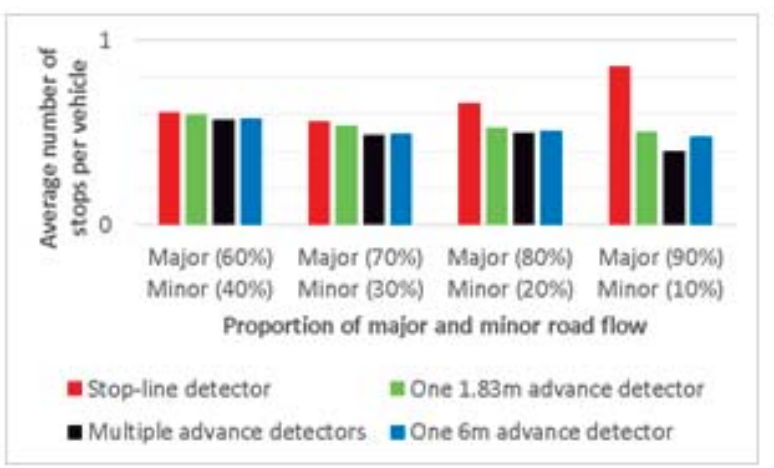

(b) Average number of stops per vehicle vs Major and minor road flow proportion

Figura 8. Variation in proportion of flow on major and minor roads

multiple advance detection scheme showed $16.9 \%$ reduction in travel time delay and $14 \%$ reduction in the average number of stops per vehicle compared to the $1.83 \mathrm{~m}$ single advance detection scheme. For the same case, when compared to the proposed $6 \mathrm{~m}$ single advance detection scheme, the multiple advance detection scheme showed $13.6 \%$ reduction in delay and $7 \%$ reduction in the average number of stops per vehicle. In this scenario, since the $\mathrm{v} / \mathrm{c}$ ratio is taken as 0.8 , the multiple advance detection scheme was able to perform better than other schemes by taking the advantage of both $6 \mathrm{~m}$ and $1.83 \mathrm{~m}$ detectors in detecting and serving more vehicles.

\subsubsection{Variation in proportion of flow on major and minor roads}

In this scenario, the flow proportion on major road $(\mathrm{EB}, \mathrm{WB})$ and minor road $(\mathrm{NB}, \mathrm{SB})$ in total flow is varied as shown in Table 7 . The volume to capacity ratio is kept constant as 0.8 and $90 \%$ Cars, $10 \%$ HV's are assumed in the traffic flow.

The simulation results of this scenario are shown in Figure 8. In this scenario, the multiple advance detection scheme has also shown better performance compared to all other detection schemes with the benefits being higher when the proportion of major road flow is high. When the major road flow proportion was $90 \%$, multiple advance detection scheme showed $17.1 \%$ reduction in travel time delay and $21.5 \%$ reduction in the average number of stops per vehicle compared to the $1.83 \mathrm{~m}$ single advance detection scheme. For the same case, when compared to the proposed $6 \mathrm{~m}$ single advance detection scheme, the multiple advance detection scheme showed $4.2 \%$ reduction in delay and $16.8 \%$ reduction in the average number of stops per vehicle. However, when the major road flow was $60 \%$, the multiple advance detection scheme showed only $0.4 \%$ reduction in delay compared to the $6 \mathrm{~m}$ advance detection scheme, thus proving to be uneconomical layout.

\section{CONCLUSIONS}

This paper proposes single and multiple advance detection schemes for low-speed traffic movements, that utilizes vehicle actuations from advance detectors located upstream of the stop-line, which are able to detect spill-back queues. The performance of FHWA's stop-line detection, $1.83 \mathrm{~m}$ single advance detection, and the proposed $6 \mathrm{~m}$ single advance detection and multiple advance detection schemes was evaluated using lane-by-lane gap-out based green extension criteria with 3.0 seconds MAH. Different scenarios were tested, including varying $\mathrm{v} / \mathrm{c}$ ratio, varying the proportion of Cars and HV's in the total flow and varying the proportion of major and minor road flow. During high volume conditions, the multiple detection scheme outperformed all the detection schemes, in reducing travel time delays and average number of stops per vehicle. The multiple detection scheme has utilized the advantage of its $6 \mathrm{~m}$ long detection zone to detect more vehicles behind the $1.83 \mathrm{~m}$ detector and to place the green extension calls during the premature gapout and queue spill-back situations. However, during low volume conditions, the performance of the multiple advance detection scheme was worse compared to all other schemes, while the proposed $6 \mathrm{~m}$ advance detection scheme has shown the best performance. Hence, the $6 \mathrm{~m}$ single advance detection scheme was proved to be economically sound when compared to the multiple advance detection scheme under low volume conditions.

Future work will focus on improving the gap-out logic of the multiple advance detection scheme, by placing the $6 \mathrm{~m}$ detectors 3.0 seconds before the stop-line and $1.83 \mathrm{~m}$ detectors 6.0 seconds before the stop-line. The $6 \mathrm{~m}$ presence mode detectors can be used to serve the queued-up vehicles before the stop-line. Once the $6 \mathrm{~m}$ detectors reach gap-out condition, the $1.83 \mathrm{~m}$ pulse mode detectors checks for any vehicle actuations and places the call for green extension accordingly. It is believed that this strategy could perform better under low $\mathrm{v} / \mathrm{c}$ ratios. 
The simulation results presented in this paper were performed on a hypothetical intersection, in the German traffic simulator VISSIM, as it allows the users to access the vehicle information from the detectors and manipulate the traffic signal timings via a COM-API interface. The saturation flow rate for the simulated intersection was found to be $2030 \mathrm{pcu} / \mathrm{hr} /$ lane using the default calibration parameters values defined in VISSIM. However, in the field, it is not rare to observe different saturation flow rates for each movement at a signalized intersection. Moreover, in VISSIM it is not possible to define saturation flow rates explicitly. The driving behavior parameters have to be changed in order to get a relevant field saturation flow rate. Future work will focus on performing the simulation on real-world intersections, considering more saturation flow rates, calibrating and validating the simulated environments to different local infrastructure, operational and driver behavior conditions, thus enabling an even more comprehensive test of the proposed detection scheme's performance potential.

\section{REFERENCES}

Bonneson, J. A., McCoy, P. T., e Moen, B. A. (1994) Traffic detector design and evaluation guidelines. Research Report, TRP-02-31-93, Nebraska Department of Roads, Nebraska, USA.

Bonneson, J. A., Sunkari, S., e Pratt, M. (2009) Traffic Signal Operations Handbook. Federal Highway Administration Report, FHWA/TX-09/0-5629-P1, Texas Department of Transportation, Texas, USA.

DfT (1997) The "MOVA" signal control system. Traffic advisory leaflet 3/97, Department of Transport, UK.

Hulscher, F. R. (1976) Selection of Vehicle Detectors for Traffic Management. Traffic Engineering and Control, Transport and Road Research Laboratory, UK.

Hunt, P.B., Bretherton, R. D., Robertson, D. I., e Royal, M. C. (1982) The SCOOT online traffic signal optimization technique. Traffic Engineering and Control, v. 23, p. 190-192.

ITSJPO (2014) Intelligent Transportation Systems Joint Program Office. Unit Cost Entries for Inductive Loop Surveillance on Corridor. Disponível em: <

http://www.itscosts.its.dot.gov/ITS/benecost.nsf/DisplayRUCBy UnitCostElementUnadjusted?ReadForm\&UnitCostElement=Indu ctive + Loop + Surveillance + on + Corridor $+\&$ Subsystem $=$ Roadside + Detection+(RS-D)> Acesso em: 10 de Jul. 2015.

Kay, J. L., Henry, R. D., e Smith, S. A. (1975) Locating Detectors for Advanced Traffic Control Strategies. Federal Highway Administration Report, FHWA-RD-75-91, U.S Department of Transportation, Washington, DC, USA.

Koonce, P. (2008) Traffic Signal Timing Manual. Federal Highway Administration Report, FHWA-HOP-08-024, U.S Department of Transportation, Washington, DC, USA.

Lin, F. B. (1985) Optimal Timing Settings and Detector Lengths of Presence Mode Full-Actuated Control. Transportation Research Record 1010, p. 37-45.

PTV (2012) VISSIM 5.40 User Manual. PTV Planung Transport Verkehr AG, Karlsruhe, Germany.
Sims, A. G., e Dobinson, K., W. (1980) The Sydney Coordinated Adaptive Traffic (SCAT) System Philosophy and Benefits. IEEE Transactions on Vehicular Technology, v. 29, n. 2, p. 130-137. DOI: $10.1109 /$ T-VT.1980.23833

Smaglik, E., Bullock, D., e Urbanik, T. (2005) Evaluation of Lane-by-Lane Vehicle Detection for Actuated Controllers Serving Multilane Approaches. Transportation Research Record 1925, p. 123-133. DOI: 10.3141/1925-13

Stevanovic, A. (2010) Adaptive Traffic Control Systems: Domestic and Foreign State of Practice - A Synthesis of Highway Practice. NCHRP Synthesis 403, Transportation Research Board, National Research Council, Washington, DC.

Tian, Z. e Urbanik, T. (2006) Green Extension and Traffic Detection Schemes at Signalized Intersections. Transportation Research Record 1978, p. 16-24. DOI: 10.3141/1978-05

Wang, X. (2008) Evaluation of Lane-by-Lane Detection at Signalized Intersections Using Simulation. ITE Journal, v. 78, n. 11, p. 16-21.

Zimmerman, K., e Bonneson, J. A. (2006) In-Service Evaluation of Detection-Control System for Isolated High-Speed Signalized Intersections. Transportation Research Record 1978, p. 34-41. DOI: $10.3141 / 1978-07$ 